\title{
A study on the density and excess molar volume of the mixture formed by 2-amino-2-methyl-1-propanol, diethanolamine, and water
}

\author{
L. F. Ramírez-Verduzco \\ Instituto Mexicano del Petróleo, \\ Eje Lázaro Cárdenas Norte 152, 07730, CDMX, México. \\ Dirección de Investigación en Transformación de Hidrocarburos. \\ Gerencia de Transformación en Biomasa. \\ e-mail:lframir@imp.mx
}

Received 23 January 2020; accepted 19 March 2020

\begin{abstract}
Aqueous alkanolamines solutions are widely used in petroleum refineries to remove acid gases from hydrotreated streams. The knowledge of physical properties in this kind of solutions is useful for the correct design, operation, and control of sweetening processes, for that, we carried out a study on the density of the ternary mixture: 2-Amino-2-Methyl-1-Propanol (AMP) + Diethanolamine (DEA) + Water (H2O). Density was measured using the vibrating tube method with an uncertainty of $2 \times 10-4 \mathrm{~g} \cdot \mathrm{cm}^{-3}$. The experimental data were obtained in the entire concentration range, temperatures from 303.15 to $333.15 \mathrm{~K}$, and pressure of $101.3 \mathrm{kPa}$. Besides, three prediction methods were tested to estimate the density of the blend: mixing rule, polynomial correlation, and excess molar volume. The best prediction was obtained through the excess molar volume through the combination of Redlich-Kister and Cibulka equations, obtaining an average absolute deviation (AAD) of $0.02 \%$, correlation coefficient $(R)$ of 0.9999 , and standard deviation $(\sigma)$ of $3 \times 10^{-4} \mathrm{~g} \cdot \mathrm{cm}^{-3}$.
\end{abstract}

Keywords: Ternary system; aqueous alkanolamine solutions; density; excess molar volume.

DOI: https://doi.org/10.31349/RevMexFis.66.504

\section{Introduction}

Hydrogen sulfide $\left(\mathrm{H}_{2} \mathrm{~S}\right)$ and carbon dioxide $\left(\mathrm{CO}_{2}\right)$ are called "Acid Gases" which are removed from gas streams by sweetening processes in refineries. The above are requirements either to purify a gas stream for further use in a process or environmental reasons.

The most common sweetening process is carried out by using aqueous alkanolamine solutions, which have excellent absorption characteristics and good stripping properties. Blended alkanolamines combine the absorption characteristics of the constituent amines, hence, giving higher loading capacity, faster reaction rates, and lesser energy requirement for regeneration. An example of an aqueous alkanolamines solution is the blend formed with AMP, DEA, and $\mathrm{H}_{2} \mathrm{O}$, which has been widely studied by our researcher group [1,2], and it is still under study in our laboratory with the aims to complete a reliable set of thermophysical and phase equilibria properties, which will define its ability to be used as a solvent for the sweetening of different hydrocarbon streams [1].

Aqueous alkanolamine solutions have been used for the absorption of acid gases since 1930. The monoethanolamine (MEA) is the most alkanolamine used up to date. MEA aqueous solution is extensively used in the electric power industry for directly scrubbing $\mathrm{CO}_{2}$ from the exhaust gas produced by fossil fuel combustion [2]. The physical and chemical properties of different alkanolamines, such as diethanolamine (DEA), methyl-diethanolamine (MDEA), butyl-diethanolamine (BDA), Triethanolamine (TEA), and propyl-ethanolamine (PEA), among others, have been studied by various research groups [3-6]. Several studies have been published on the density of alkanolamines, due to this property plays an important role in the design, operation, and control of sweetening processes. Also, the solution density is important in the mass transfer rate modeling of absorbers and regenerators. Some studies on density are mentioned below.

Yoon et al. 2002 [7] studied the density of the 2-amino2-ethyl-1,3-propanediol $+\mathrm{H}_{2} \mathrm{O}$ mixture, which was measured by using a calibrated pycnometer at temperatures from 303.15 to $343.15 \mathrm{~K}$. The density values were correlated using a quadratic polynomial equation, where predictions had an ADD of $7.05 \times 10^{-2} \%$.

The densities of aqueous blends of alkanolamines (MDEA, AMP, MEA, and DEA) at temperatures from 298.15 to $323.15 \mathrm{~K}$ were measured by Mandal et al. 2003 [8], where a Gay-Lussac pycnometer was used. To correlate the density of liquid mixtures, a Redlich-Kister type equation for the excess molar volume was applied by Mandal et al. Their predictions show a good agreement with the experimental data, with an ADD of $0.1 \%$.

In 2006, Rebolledo-Libreros and Trejo [9] reported the experimental values of density for aqueous solutions of three alkanolamines (MDEA, DEA, and AMP). The density of the alkanolamine solutions was measured using a Sodev 03D vibrating tube densimeter. The experimental density data were correlated by using a linear equation by Rebolledo-Libreros and Trejo, who obtained a $\sigma$ of $4 \times 10^{-5} \mathrm{~g} \cdot \mathrm{cm}^{-3}$ in its prediction.

Álvarez et al. reported in 2010 [10] the density of mixtures of the following alkanolamines solutions: MEA + AMP, MEA + TEA, and MEA + MDEA, covering the entire composition range and temperatures from $293.15 \mathrm{~K}$ to $323.15 \mathrm{~K}$, where the experimental values of density were used to esti- 
mate the excess molar volume. Those authors used an Anton Paar D SA 5000 densimeter to made their experimental measurements, with uncertainty in the density of $5 \times 10^{-5}$ $\mathrm{g} \cdot \mathrm{cm}^{-3}$, a Redlich-Kister type equation was used to correlate the excess molar volumes.

The density of the ternary solution of MDEA + MEA + ethanol (EtOH) was recently reported by Ma et al. 2019 [11], those authors used a vibrating tube densimeter to obtain their experimental measurements in density. The excess molar volumes were estimated from the experimental density data. The excess molar volume was correlated by the Redlich-Kister and Cibulka's equations. Also those authors analyzed the intermolecular interactions of the ternary solution. Their predictions on the excess molar volume had a $\sigma$ in the range of 0.02 to $0.05 \mathrm{~cm}^{3} \cdot \mathrm{mol}^{-1}$.

Most of the experimental works reported on phase equilibria or thermophysical properties of aqueous alkanolamine solutions have been carried out in a limited alkanolamine concentration range (e.g., between 0 to 0.2 in mole fraction [2], that corresponds to the zone rich in water), which it is commonly used in the industry.

Considering the importance of aqueous alkanolamine solutions, we carried out an experimental and theoretical study on the density of the blend formed by AMP, DEA, and $\mathrm{H}_{2} \mathrm{O}$, covering the whole concentration range, temperatures from 303.15 to $333.15 \mathrm{~K}$, and pressure of $101.3 \mathrm{kPa}$.

Two hundred sixty-four experimental points of density were measured for the ternary mixture: AMP (1) + DEA (2) $+\mathrm{H}_{2} \mathrm{O}$ (3), with an uncertainty of $2 \times 10^{-4} \mathrm{~g} \cdot \mathrm{cm}^{-3}$.

Besides, three prediction methods to estimate the density of the ternary mixture were tested (mixing rule, polynomial correlation, and excess molar volume), all the above methods were developed as a function of the temperature and composition of the blend, being the excess molar volume, the best method to predict the density of the ternary system studied, where the excess molar volume was correlated through the equations proposed by Redlich-Kister and Cibulka.

The importance of our work is that the experimental results on density include either pure alkanolamines or aqueous mixtures at low and high alkanolamine concentration, covering the entire concentration range. Also we develop methods to predict the density of this aqueous solution. Besides our density data can be used in the sweetening units of the refining processes, as well as in different correlations to derive other properties, like surface tension, heat capacity, and viscosity, among others. In this work, AMP, DEA, and $\mathrm{H}_{2} \mathrm{O}$ were denoted as compound (1), (2), and (3) respectively.

\section{Experimental and theoretical methodology}

\subsection{Materials}

Table I reports the characteristics of the materials that were used to carry out our study on density.

\subsection{Measurements}

Various blends were prepared by using an analytical balance (A\&D ER-182A). The samples were degassed using an ultrasound bath. Density measurements were carried out in a vibrating tube densitometer (Sodev) following a methodology reported in previous works by our research group [2,7]. Density was measured at $101.3 \mathrm{kPa}$ (with an uncertainty of $0.1 \mathrm{kPa}$ ), and under isothermal conditions by using a Haake FK circulating bath, where the temperature was measured using a quartz sensor joined to Hewlett-Packard 2804A digital thermometer, with an uncertainty of $1 \times 10^{-2} \mathrm{~K}$. Density was obtained into an average period of vibration from at least twenty stable measurements with an uncertainty of $2 \times 10^{-4} \mathrm{~g} \cdot \mathrm{cm}^{-3}$. Once the density values were obtained experimentally, a series of equations were used to derive the excess molar volumes, as it is described below.

First, the molar volume of pure components $\left(V_{i}^{0}\right)$, expressed in $\mathrm{cm}^{3} \cdot \mathrm{mol}^{-1}$, was calculated by relating density and molecular weight as follows.

$$
V-i^{0}=\frac{M_{i}}{\rho_{i}},
$$

where $M_{i}$ is the molecular weight of the $i-t h$ compound, expressed in $\mathrm{g} \cdot \mathrm{mol}^{-1}$; and $\rho_{i}$ is the density of the $i-t h \mathrm{com}$ pound, expressed in $\mathrm{g} \cdot \mathrm{cm}^{-3}$.

TABLE I. Properties of the pure compounds.

\begin{tabular}{|c|c|c|c|c|c|}
\hline Chemical & CAS & & Purification & & Analysis \\
\hline Name & & Source & Method & Purity & Method \\
\hline $\mathrm{AMP}^{a}$ & $124-68-5$ & Aldrich & Distillation & 0.995 mole fraction & $\mathrm{GC}^{d}$ \\
\hline $\mathrm{DEA}^{b}$ & $111-42-2$ & J.T. Baker & Distillation & 0.991 mole fraction & $\mathrm{GC}^{d}$ \\
\hline $\mathrm{H}_{2} \mathrm{O}^{c}$ & $7732-18-5$ & - & $\begin{array}{l}\text { Bidistillation } \\
\text { and } \\
\text { Deionization }\end{array}$ & $\leq 2 \times 10^{-6} \mathrm{ohm}^{-1} \mathrm{~cm}^{-1}$ & Conductivity \\
\hline
\end{tabular}

${ }^{a}$ AMP $=$ 2-Amino-2-Methyl-1-Propanol. ${ }^{b}$ DEA $=$ Diethanolamine. ${ }^{c} \mathrm{H}_{2} \mathrm{O}=$ Water. ${ }^{d}$ Gas-liquid chromatography. 
Secondly, the molar volume of the mixture $\left(V_{m}\right)$ was obtained using Eq. (2).

$$
V_{m}=\frac{\sum_{i=1}^{n} x_{i} M_{i}}{\rho_{m}},
$$

where $x_{i}$ is the mole fraction of the $i-t h$ compound, $\rho_{m}$ is the density of the blend expressed in $\mathrm{g} \cdot \mathrm{cm}^{-3}$, and $\mathrm{Vm}$ is the molar volume of the mixture expressed in $\mathrm{cm}^{3} \cdot \mathrm{mol}^{-1}$.

Finally, the experimental excess molar volume $\left(V_{m}^{E}\right)$ was derived form employing Eq. (3).

$$
V_{m}^{E}=V_{m}-\sum_{i=0}^{n} x_{i} V_{i}^{0},
$$

\subsection{Prediction methods}

Three prediction methods were tested to estimate the density of pure, binary, and ternary blends formed by AMP, DEA, and $\mathrm{H}_{2} \mathrm{O}$. The first method is based on a polynomial correlation, while the second one is based on a mixing rule; these methods were chosen due they are easy to implement as a function of temperature and concentration of the blend. The third method is based on the Redlich-Kister equation, which was chosen because it is the most frequent method to analyze the density and excess molar volume in the literature. The prediction capability of the methods used in this work was tested through four statistical parameters, which are: the relative error $(\varepsilon)$, average absolute deviation $(A A D)$, correlation coefficient $(R)$, and standard deviation $(\sigma)$. The mathematical expressions for each parameter are given by Eqs. (4), (5), (6), and (7).

$$
\varepsilon=\frac{f_{\exp , i}-f_{\mathrm{cal}, i} \times 100}{f_{\exp , i}},
$$

where $f$ is a physical variable, in our case, it represents the density or the excess molar volume, and $\varepsilon$ is the relative error expressed in $\%$

$$
A A D=\frac{\sum_{i=0}^{n}\left(\frac{f_{\mathrm{exp}, i}-f_{\mathrm{cal}, i} \times 100}{f_{\mathrm{exp}, i}}\right)}{n}
$$

where $n$ is the number of experimental or calculated points, and $A A D$ is the average absolute deviation expressed in $\%$

$$
R=\frac{\sum_{i=0}^{n}\left(f_{\exp , i}-f_{\exp }^{-}\right)\left(f_{\mathrm{cal}, i}-\overline{f_{\mathrm{cal}}}\right)}{\sqrt{\sum_{i=0}^{n}\left(f_{\exp , i}-f_{\exp }^{-}\right)^{2} \sum_{i=0}^{n}\left(f_{\mathrm{cal}, i}-\overline{f_{\mathrm{cal}}}\right)^{2}}},
$$

where $\bar{f}$ is the average value of the physical variable, and $R$ is the dimensionless correlation coefficient

$$
\sigma=\sqrt{\frac{\sum_{i=0}^{n}\left(f_{\exp , i}-\overline{f_{\mathrm{cal}}}\right)^{2}}{n-m}},
$$

where $m$ is the number of parameters of the correlation, and $\sigma$ is the standard deviation, expressed in $\mathrm{g} \cdot \mathrm{cm}^{-3}$ in case of density, and $\mathrm{cm}^{3} \cdot \mathrm{mol}^{-1}$ in case of the excess molar volume.

\subsubsection{Polynomial correlation}

We developed a polynomial correlation to estimate both the density of pure compounds and mixtures formed by AMP, DEA, and $\mathrm{H}_{2} \mathrm{O}$.

The experimental points obtained in this work (two hundred sixty-four) were used to adjust the parameters of the polynomial correlation, where density was calculated as a function of the temperature and concentration of the blend through Eq. (8).

$$
\rho_{m}=A+B x_{1}+C x_{2}+D T,
$$

where $\rho_{m}$ is the density of the blend expressed in $\mathrm{g} \cdot \mathrm{cm}^{-3}$, while $A, B, C$, and $D$ are adjustable parameters, and $T$ is the temperature expressed in $\mathrm{K}$. The water concentration can be calculated using the following mass balance: $x_{3}=$ $1-x_{1}-x_{2}$.

The Design-Expert v.6 software was used to adjust the parameters of the polynomial correlation, considering a twolevel factorial design with three factors $\left(x_{1}, x_{2}\right.$, and $\left.T\right)$. The analysis of variance (ANOVA) was made to establish the significance of the adjusted parameters.

\subsubsection{Mixing rule}

We used a mixing rule to predict the density of the ternary mixture. The mixing rule is given by Eq. (9), as follows:

$$
\rho_{m}=\sum_{i=1}^{n} x-i \rho_{i}
$$

where $\rho_{i}$ is the density of the $i-t h$ pure compound expressed in $\mathrm{g} \cdot \mathrm{cm}^{-3}$.

While the empirical correlation for $\rho_{i}$ is given by:

$$
\rho_{i}=A+B T+C T^{2},
$$

where $A, B$, and $C$ are adjustable parameters.

A FORTRAN program was codified to adjust the parameters of Eq. (10) by linear regression and using the experimental density of pure compounds.

\subsubsection{Excess molar volume}

This section presents the prediction methods used to estimate the excess molar volume of the binary and ternary mixtures.

\subsubsection{Binary mixtures}

The excess molar volume for the binary mixtures was correlated using the well-known Redlich-Kister equation, which is expressed as follows:

$$
V_{m, i, j}^{E}=x_{i} x_{j} \sum_{k=0}^{m-1} A_{k}\left(x_{i}-x_{j}\right)^{k},
$$

where $A_{k}$ are adjustable parameters, and $\mathrm{m}$ is the number of parameters. 


\subsubsection{Ternary mixtures}

The excess molar volume for the ternary mixture was estimated according to the following expression:

$$
V_{m, 123}^{E}=V_{m, b i n}^{E}+V_{m, t e r}^{E},
$$

where $V_{m, b i n}^{E}$ and $V_{m, t e r}^{E}$ are the binary and ternary contribution to the excess molar volume expressed in $\mathrm{cm}^{3} \cdot \mathrm{mol}^{-1}$.

$V_{m, b i n}^{E}$ can be calculated by the sum of the excess molar volumes of each binary mixture, as follows:

$$
V_{m, b i n}^{E}=V_{m, 12}^{E}+V_{m, 13}^{E}+V_{m, 23}^{E},
$$

where $V_{m, 12}^{E}, V_{m, 13}^{E}$, and $V_{m, 23}^{E}$ are obtained from Eq. (11).

We considered using the methods proposed by Cibulka and Singh to estimate the ternary contribution to the excess molar volume, which are expressed as:

1. Cibulka [13]:

$$
V_{m, t e r}^{E}=x_{1} x_{2} x_{3}\left(B_{0}+B-1 x_{1}+B_{2} x_{2}\right) .
$$

2. Singh et al. [14]:

$$
\begin{aligned}
V_{m, t e r}^{E} & =x_{1} x_{2} x_{3}\left(B_{0}+B-1 x_{1}\left(x_{2}-x_{3}\right)\right. \\
& \left.+B_{2} x_{1}^{2}\left(x_{2}-x_{3}\right)^{2}\right),
\end{aligned}
$$

where $B_{i}$ are adjustable parameters.

\section{Results and discussion}

In this section, we present the main results and discussion of our study on the density of the following issues. Experimental measurements and prediction.

\subsection{Pure compounds}

The experimental results on density $(\rho)$ of the pure compounds are shown in Table II. We obtained an excellent agree-

\begin{tabular}{|c|c|c|c|}
\hline Compound & $T, \mathrm{~K}$ & This work $^{a}$ & Data from literature $\rho \mathrm{g} \cdot \mathrm{cm}^{-3}$ \\
\hline \multirow{4}{*}{ AMP } & 303.15 & 0.9267 & $0.9255[2], 0.9273[15], 0.9267[16]$ \\
\hline & 313.15 & 0.9182 & $0.9172[2], 0.9211[15], 0.9179[16]$ \\
\hline & 323.15 & 0.9097 & $0.9092[2], 0.9134[15], 0.9096[16]$ \\
\hline & 333.15 & 0.9012 & $0.9007[2], 0.9055[1], 0.9011[16]$ \\
\hline \multirow{4}{*}{ DEA } & 303.15 & 1.0911 & $1.0909[12], 1.09048[17], 1.0922 \mathrm{~b}[18]$ \\
\hline & 313.15 & 1.0841 & 1.0847 [2], 1.0838 [12], 1.08401 [17], 1.0846b [18], 1.0843 [19] \\
\hline & 323.15 & 1.0772 & $1.0774[2], 1.0771[12], 1.07732[17], 1.0781 \mathrm{~b}[18], 1.0778$ [19] \\
\hline & 333.15 & 1.0702 & $1.0703[2], 1.070[12], 1.07174[17], 1.0715 \mathrm{~b}[18]$ \\
\hline \multirow{4}{*}{$\mathrm{H}_{2} \mathrm{O}$} & 303.15 & 0.9953 & $0.99565[17], 0.99565[20]$ \\
\hline & 313.15 & 0.9921 & $0.99222[17], 0.99222[20]$ \\
\hline & 323.15 & 0.9882 & 0.98804 [17], 0.98804 [20] \\
\hline & 333.15 & 0.9836 & $0.9832[17], 0.9832[20]$ \\
\hline
\end{tabular}
ment with the corresponding ones that are reported in the literature; in a comparison of thirty-seven points, an AAD of $0.27 \%$ was obtained.

\begin{tabular}{|c|c|c|c|c|c|c|c|c|c|c|}
\hline$x_{1}$ & $x_{2}$ & $x_{3}$ & $\begin{array}{c}\rho \\
\mathrm{g} \cdot \mathrm{cm}^{-3}\end{array}$ & $\begin{array}{c}V_{m}^{E} \\
\mathrm{~cm}^{3} \cdot \mathrm{mol}^{-1}\end{array}$ & $\begin{array}{c}\rho \\
\mathrm{g} \cdot \mathrm{cm}^{-3}\end{array}$ & $\begin{array}{c}V_{m}^{E} \\
\mathrm{~cm}^{3} \cdot \mathrm{mol}^{-1}\end{array}$ & $\begin{array}{c}\rho \\
\mathrm{g} \cdot \mathrm{cm}^{-3}\end{array}$ & $\begin{array}{c}V_{m}^{E} \\
\mathrm{~cm}^{3} \cdot \mathrm{mol}^{-1}\end{array}$ & $\begin{array}{c}\rho \\
\mathrm{g} \cdot \mathrm{cm}^{-3}\end{array}$ & $\begin{array}{c}V_{m}^{E} \\
\mathrm{~cm}^{3} \cdot \mathrm{mol}^{-1}\end{array}$ \\
\hline & & & \multicolumn{2}{|c|}{$303.15 \mathrm{~K}$} & \multicolumn{2}{|c|}{$313.15 \mathrm{~K}$} & \multicolumn{2}{|c|}{$323.15 \mathrm{~K}$} & \multicolumn{2}{|c|}{$333.15 \mathrm{~K}$} \\
\hline 0.9007 & 0.0993 & 0 & 0.9435 & -0.046 & 0.935 & -0.035 & 0.9265 & -0.024 & 0.9181 & -0.024 \\
\hline 0.8006 & 0.1994 & 0 & 0.9605 & -0.097 & 0.952 & -0.076 & 0.9436 & -0.063 & 0.9352 & -0.051 \\
\hline 0.7004 & 0.2996 & 0 & 0.9773 & -0.126 & 0.969 & -0.113 & 0.9607 & -0.097 & 0.9525 & -0.094 \\
\hline 0.5998 & 0.4002 & 0 & 0.9942 & -0.159 & 0.986 & -0.142 & 0.9779 & -0.132 & 0.9698 & -0.126 \\
\hline 0.5005 & 0.4995 & 0 & 1.0107 & -0.172 & 1.0026 & -0.152 & 0.9947 & -0.147 & 0.9867 & -0.137 \\
\hline 0.3997 & 0.6003 & 0 & 1.0273 & -0.173 & 1.0193 & -0.148 & 1.0116 & -0.146 & 1.0038 & -0.14 \\
\hline 0.3002 & 0.6998 & 0 & 1.0435 & -0.156 & 1.0357 & -0.135 & 1.0281 & -0.126 & 1.0205 & -0.123 \\
\hline
\end{tabular}

TABLE II. Experimental density $(\rho)$ of the liquid pure compounds.

${ }^{a}$ Standard uncertainty, $\rho$ is $0.0002 \mathrm{~g} / \mathrm{cm}^{3}$ and T is $0.01 \mathrm{~K} .{ }^{b}$ Obtained by interpolation of values reported by DiGuillo et al. [18].

TABLE III. Experimental density $(\rho)$ and excess molar volume $\left(V_{m}^{E}\right)$ at different temperatures. 


\begin{tabular}{|c|c|c|c|c|c|c|c|c|c|c|}
\hline$x_{1}$ & $x_{2}$ & $x_{3}$ & $\begin{array}{c}\rho \\
\mathrm{g} \cdot \mathrm{cm}^{-3}\end{array}$ & $\begin{array}{c}V_{m}^{E} \\
\mathrm{~cm}^{3} \cdot \mathrm{mol}^{-1}\end{array}$ & $\begin{array}{c}\rho \\
\mathrm{g} \cdot \mathrm{cm}^{-3} \\
\end{array}$ & $\begin{array}{c}V_{m}^{E} \\
\mathrm{~cm}^{3} \cdot \mathrm{mol}^{-1}\end{array}$ & $\begin{array}{c}\rho \\
\mathrm{g} \cdot \mathrm{cm}^{-3} \\
\end{array}$ & $\begin{array}{c}V_{m}^{E} \\
\mathrm{~cm}^{3} \cdot \mathrm{mol}^{-1}\end{array}$ & $\begin{array}{c}\rho \\
\mathrm{g} \cdot \mathrm{cm}^{-3}\end{array}$ & $\begin{array}{c}V_{m}^{E} \\
\mathrm{~cm}^{3} \cdot \mathrm{mol}^{-1}\end{array}$ \\
\hline & & & \multicolumn{2}{|c|}{$303.15 \mathrm{~K}$} & \multicolumn{2}{|c|}{$313.15 \mathrm{~K}$} & \multicolumn{2}{|c|}{$323.15 \mathrm{~K}$} & \multicolumn{2}{|c|}{$333.15 \mathrm{~K}$} \\
\hline 0.1998 & 0.8002 & 0 & 1.0597 & -0.127 & 1.052 & -0.099 & 1.0446 & -0.091 & 1.0372 & -0.09 \\
\hline 0.0999 & 0.9001 & 0 & 1.0755 & -0.071 & 1.0681 & -0.053 & 1.0609 & -0.045 & 1.0537 & -0.045 \\
\hline 0.9001 & 0 & 0.0999 & 0.9316 & -0.332 & 0.9229 & -0.309 & 0.9141 & -0.277 & 0.9056 & -0.275 \\
\hline 0.7991 & 0.1003 & 0.1006 & 0.9512 & -0.474 & 0.942 & -0.395 & 0.9327 & -0.305 & 0.9237 & -0.243 \\
\hline 0.6998 & 0.2001 & 0.1001 & 0.97 & -0.55 & 0.9608 & -0.463 & 0.9513 & -0.343 & 0.9418 & -0.222 \\
\hline 0.6002 & 0.2998 & 0.1 & 0.9891 & -0.652 & 0.9797 & -0.536 & 0.9697 & -0.36 & 0.9601 & -0.22 \\
\hline 0.4997 & 0.3996 & 0.1007 & 1.0081 & -0.734 & 0.9988 & -0.617 & 0.9885 & -0.404 & 0.9786 & -0.225 \\
\hline 0.3997 & 0.5004 & 0.0999 & 1.0265 & -0.758 & 1.0175 & -0.656 & 1.0072 & -0.431 & 0.997 & -0.214 \\
\hline 0.3004 & 0.5994 & 0.1002 & 1.0437 & -0.7 & 1.0352 & -0.626 & 1.0253 & -0.423 & 1.0153 & -0.212 \\
\hline 0.1998 & 0.6992 & 0.101 & 1.0602 & -0.568 & 1.0523 & -0.528 & 1.0429 & -0.353 & 1.0336 & -0.189 \\
\hline 0.1005 & 0.8001 & 0.0994 & 1.0757 & -0.37 & 1.0683 & -0.352 & 1.06 & -0.252 & 1.0517 & -0.158 \\
\hline 0 & 0.8992 & 0.1008 & 1.0902 & -0.087 & 1.0835 & -0.106 & 1.0767 & -0.11 & 1.07 & -0.133 \\
\hline 0.8004 & 0 & 0.1996 & 0.9368 & -0.604 & 0.928 & -0.57 & 0.9192 & -0.537 & 0.9105 & -0.515 \\
\hline 0.6997 & 0.1001 & 0.2002 & 0.9583 & -0.743 & 0.9489 & -0.649 & 0.9396 & -0.562 & 0.9301 & -0.458 \\
\hline 0.5996 & 0.2004 & 0.2 & 0.9794 & -0.842 & 0.9698 & -0.723 & 0.9597 & -0.558 & 0.9498 & -0.409 \\
\hline 0.5002 & 0.2997 & 0.2001 & 1.0005 & -0.953 & 0.9908 & -0.816 & 0.9799 & -0.576 & 0.9696 & -0.382 \\
\hline 0.4008 & 0.3997 & 0.1995 & 1.0213 & -1.031 & 1.0117 & -0.892 & 1.0004 & -0.61 & 0.9897 & -0.374 \\
\hline 0.3002 & 0.4995 & 0.2003 & 1.041 & -1.013 & 1.0319 & -0.901 & 1.0208 & -0.624 & 1.0097 & -0.345 \\
\hline 0.2001 & 0.5991 & 0.2008 & 1.059 & -0.873 & 1.0507 & -0.806 & 1.0406 & -0.594 & 1.0299 & -0.336 \\
\hline 0.1004 & 0.6992 & 0.2004 & 1.0751 & -0.6 & 1.0677 & -0.581 & 1.0588 & -0.443 & 1.0498 & -0.302 \\
\hline 0 & 0.8004 & 0.1996 & 1.0898 & -0.221 & 1.0832 & -0.24 & 1.0765 & -0.248 & 1.0698 & -0.265 \\
\hline 0.6992 & 0 & 0.3008 & 0.9427 & -0.838 & 0.934 & -0.808 & 0.925 & -0.759 & 0.9163 & -0.735 \\
\hline 0.5998 & 0.1004 & 0.2998 & 0.9657 & -0.907 & 0.9567 & -0.845 & 0.9475 & -0.768 & 0.9378 & -0.655 \\
\hline 0.5 & 0.2001 & 0.2999 & 0.9887 & -0.983 & 0.9797 & -0.91 & 0.9695 & -0.747 & 0.9596 & -0.607 \\
\hline 0.3997 & 0.3004 & 0.2999 & 1.0122 & -1.082 & 1.0029 & -0.977 & 0.992 & -0.752 & 0.9816 & -0.563 \\
\hline 0.2998 & 0.4011 & 0.2991 & 1.0348 & -1.116 & 1.0257 & -1.013 & 1.0146 & -0.764 & 1.0037 & -0.527 \\
\hline 0.1991 & 0.5007 & 0.3002 & 1.0556 & -1.026 & 1.0471 & -0.95 & 1.0367 & -0.737 & 1.0261 & -0.511 \\
\hline 0.0999 & 0.6002 & 0.2999 & 1.0736 & -0.768 & 1.0661 & -0.741 & 1.0572 & -0.614 & 1.0478 & -0.458 \\
\hline 0 & 0.7008 & 0.2992 & 1.0894 & -0.362 & 1.0829 & -0.38 & 1.0762 & -0.382 & 1.0695 & -0.395 \\
\hline 0.6009 & 0 & 0.3991 & 0.949 & -1.006 & 0.9402 & -0.965 & 0.9315 & -0.935 & 0.9228 & -0.91 \\
\hline 0.5004 & 0.0995 & 0.4001 & 0.9737 & -1.007 & 0.9654 & -0.988 & 0.9565 & -0.932 & 0.9472 & -0.853 \\
\hline 0.3999 & 0.2007 & 0.3994 & 0.9994 & -1.053 & 0.9909 & -1.009 & 0.9813 & -0.893 & 0.9717 & -0.781 \\
\hline 0.2995 & 0.3004 & 0.4001 & 1.0249 & -1.1 & 1.0163 & -1.036 & 1.0061 & -0.87 & 0.9959 & -0.706 \\
\hline 0.1995 & 0.4011 & 0.3994 & 1.049 & -1.056 & 1.0408 & -1.002 & 1.0308 & -0.835 & 1.0206 & -0.659 \\
\hline 0.0989 & 0.5001 & 0.401 & 1.0704 & -0.854 & 1.063 & -0.831 & 1.0543 & -0.727 & 1.0453 & -0.612 \\
\hline 0 & 0.5992 & 0.4008 & 1.0887 & -0.495 & 1.0822 & -0.504 & 1.0755 & -0.501 & 1.0688 & -0.508 \\
\hline 0.5007 & 0 & 0.4993 & 0.9562 & -1.116 & 0.9476 & -1.082 & 0.9391 & -1.06 & 0.9306 & -1.044 \\
\hline 0.3998 & 0.0997 & 0.5005 & 0.9839 & -1.084 & 0.976 & -1.078 & 0.9675 & -1.042 & 0.9592 & -1.024 \\
\hline 0.2998 & 0.1998 & 0.5004 & 1.012 & -1.075 & 1.004 & -1.049 & 0.995 & -0.97 & 0.9862 & -0.908 \\
\hline 0.1994 & 0.3008 & 0.4998 & 1.0397 & -1.038 & 1.0318 & -1.002 & 1.0228 & -0.907 & 1.0135 & -0.802 \\
\hline 0.0998 & 0.4008 & 0.4994 & 1.065 & -0.892 & 1.0577 & -0.87 & 1.0494 & -0.796 & 1.0407 & -0.709 \\
\hline 0 & 0.4995 & 0.5005 & 1.0873 & -0.598 & 1.0808 & -0.598 & 1.0741 & -0.589 & 1.0673 & -0.586 \\
\hline 0.3996 & 0 & 0.6004 & 0.965 & -1.184 & 0.9567 & -1.158 & 0.9482 & -1.128 & 0.9396 & -1.1 \\
\hline 0.2994 & 0.1008 & 0.5998 & 0.9969 & -1.128 & 0.9889 & -1.102 & 0.9806 & -1.067 & 0.9728 & -1.066 \\
\hline 0.2007 & 0.1997 & 0.5996 & 1.0275 & -1.043 & 1.0197 & -1.011 & 1.0114 & -0.96 & 1.0033 & -0.928 \\
\hline 0.1008 & 0.2997 & 0.5995 & 1.0571 & -0.902 & 1.0498 & -0.875 & 1.042 & -0.83 & 1.0339 & -0.78 \\
\hline 0 & 0.4006 & 0.5994 & 1.0843 & -0.648 & 1.0779 & -0.643 & 1.0713 & -0.632 & 1.0646 & -0.628 \\
\hline 0.3008 & 0 & 0.6992 & 0.9752 & -1.178 & 0.9669 & -1.14 & 0.9584 & -1.101 & 0.9501 & -1.08 \\
\hline
\end{tabular}




\begin{tabular}{|c|c|c|c|c|c|c|c|c|c|c|}
\hline$x_{1}$ & $x_{2}$ & $x_{3}$ & $\begin{array}{c}\rho \\
\mathrm{g} \cdot \mathrm{cm}^{-3}\end{array}$ & $\begin{array}{c}V_{m}^{E} \\
\mathrm{~cm}^{3} \cdot \mathrm{mol}^{-1}\end{array}$ & $\begin{array}{c}\rho \\
\mathrm{g} \cdot \mathrm{cm}^{-3}\end{array}$ & $\begin{array}{c}V_{m}^{E} \\
\mathrm{~cm}^{3} \cdot \mathrm{mol}^{-1}\end{array}$ & $\begin{array}{c}\rho \\
\mathrm{g} \cdot \mathrm{cm}^{-3}\end{array}$ & $\begin{array}{c}V_{m}^{E} \\
\mathrm{~cm}^{3} \cdot \mathrm{mol}^{-1}\end{array}$ & $\begin{array}{c}\rho \\
\mathrm{g} \cdot \mathrm{cm}^{-3}\end{array}$ & $\begin{array}{c}V_{m}^{E} \\
\mathrm{~cm}^{3} \cdot \mathrm{mol}^{-1}\end{array}$ \\
\hline & & & \multicolumn{2}{|c|}{$303.15 \mathrm{~K}$} & \multicolumn{2}{|c|}{$313.15 \mathrm{~K}$} & \multicolumn{2}{|c|}{$323.15 \mathrm{~K}$} & \multicolumn{2}{|c|}{$333.15 \mathrm{~K}$} \\
\hline 0.1005 & 0.2004 & 0.6991 & 1.0461 & -0.887 & 1.0388 & -0.856 & 1.0313 & -0.823 & 1.0238 & -0.801 \\
\hline 0 & 0.3005 & 0.6995 & 1.0783 & -0.631 & 1.0721 & -0.622 & 1.0656 & -0.607 & 1.0591 & -0.604 \\
\hline 0.1005 & 0.2004 & 0.6991 & 1.0461 & -0.887 & 1.0388 & -0.856 & 1.0313 & -0.823 & 1.0238 & -0.801 \\
\hline 0 & 0.3005 & 0.6995 & 1.0783 & -0.631 & 1.0721 & -0.622 & 1.0656 & -0.607 & 1.0591 & -0.604 \\
\hline 0.1997 & 0 & 0.8003 & 0.9865 & -1.035 & 0.9787 & -0.999 & 0.9705 & -0.96 & 0.9624 & -0.933 \\
\hline 0.0998 & 0.0995 & 0.8007 & 1.0265 & -0.77 & 1.0206 & -0.778 & 1.0133 & -0.749 & 1.0062 & -0.738 \\
\hline 0 & 0.1998 & 0.8002 & 1.066 & $1-0.51$ & 1.0603 & -0.5 & 1.0541 & -0.485 & 1.0478 & -0.478 \\
\hline
\end{tabular}

Standard uncertainties: $\rho$ is $0.0002 \mathrm{~g} / \mathrm{cm}^{3}, T$ is $0.01 \mathrm{~K}$, and $x$ is 0.0002 .

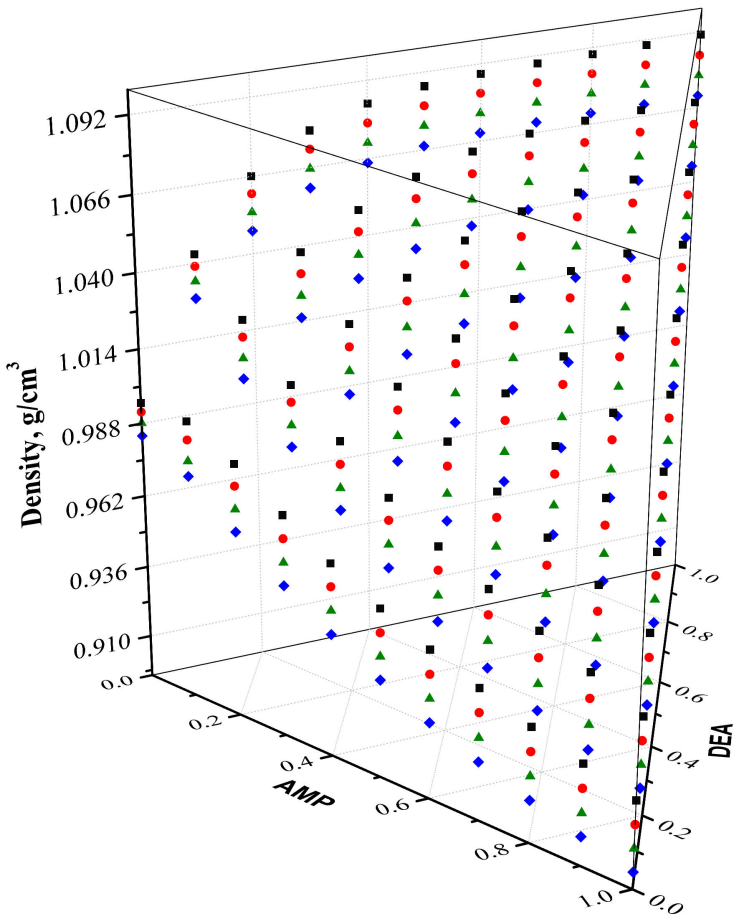

FIGURE 1. Experimental density data. $\mathrm{K}), \boldsymbol{\Delta}(323.15 \mathrm{~K})$, and $(333.15 \mathrm{~K})$.

\subsection{Alkanolamine solutions}

Table III shows the experimental results on density and excess molar volume of the blends formed with AMP, DEA, and $\mathrm{H}_{2} \mathrm{O}$.

Figure 1 shows the experimental results of density in a three-dimensional (3D) plot with the shape of a triangular prism, while Fig. 2 shows projections of the experimental densities at temperatures of 303.15 to $333.15 \mathrm{~K}$, where the higher values of density are located at a temperature of $303.15 \mathrm{~K}$ and DEA's rich concentration zone, while the lowest values of density are located at temperature of $333.15 \mathrm{~K}$, and AMP's rich concentration zone.

Figures 3, 4, and 5 present the experimental excess molar volume of the binary mixtures: AMP (1) + DEA (2), AMP (1) $+\mathrm{H}_{2} \mathrm{O}$ (3), and DEA (2) $+\mathrm{H}_{2} \mathrm{O}$ (3). Curves in plots represent the functionality of $V_{m}^{E}$ with the $T$ and xi variables, where VEm was obtained through the Redlich-Kister equation. We obtained negative values of $V_{m}^{E}$ in all binary mixtures. Low values of $V_{m}^{E}$ were observed for the AMP (1) + DEA (2) blend, which implies that this mixture is close to an ideal solution behavior. There are no previously reported values in the literature on the density of the AMP + DEA mixture to the ones presented in the study. Although, this information is relevant to derive the pair interaction between these compounds. On the other hand, high values of $V_{m}^{E}$ were observed for the AMP (1) $+\mathrm{H}_{2} \mathrm{O}$ (3) and DEA (2) $+\mathrm{H}_{2} \mathrm{O}$ (3) blends, the above is characteristic of non-ideal solutions.

\subsection{Prediction methods}

In this section, we present the results on the three prediction methods, as well as the statistical analysis that was carried out to test their predictive capability.

\subsubsection{Polynomial test}

Two hundred sixty-four experimental points were used to adjust the parameters of the polynomial correlation; the result is given by Eq. (16),

$$
\begin{aligned}
\rho_{m} & =1.28331-0.11778 x_{1}+0.082342 x_{2} \\
& -8.33409 \times 10^{-4} T
\end{aligned}
$$



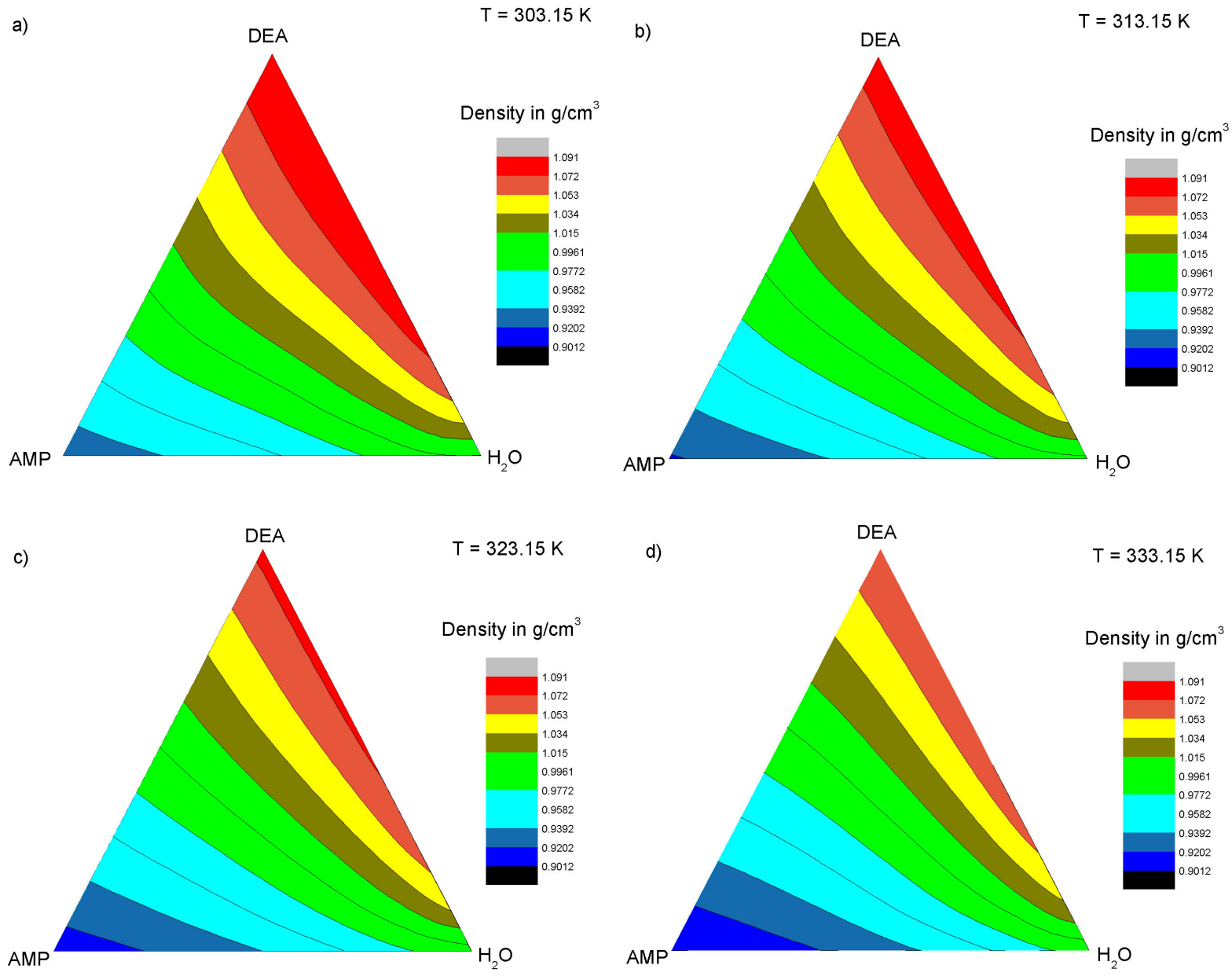

FIGURE 2. Projections of the experimental density data. a) $303.15 \mathrm{~K}$, b) $313.15 \mathrm{~K}$, c) $323.15 \mathrm{~K}$, and d) $333.15 \mathrm{~K}$.

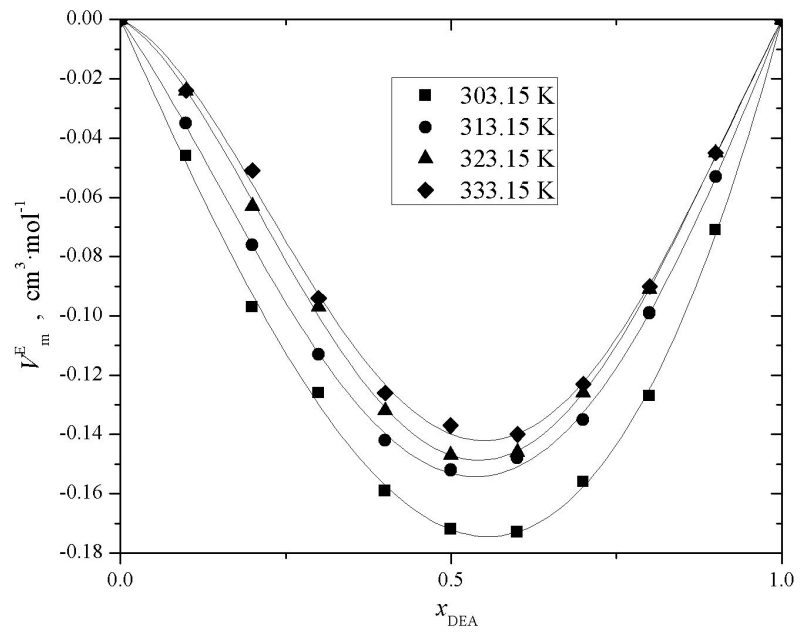

FIGURE 3. Excess molar volume of AMP (1) + DEA (2).

where density is a function of the temperature and concentration of the blend. We use the Gauss-Newton method to adjust the parameters of Eq. (16), through the minimization of the following objective function,

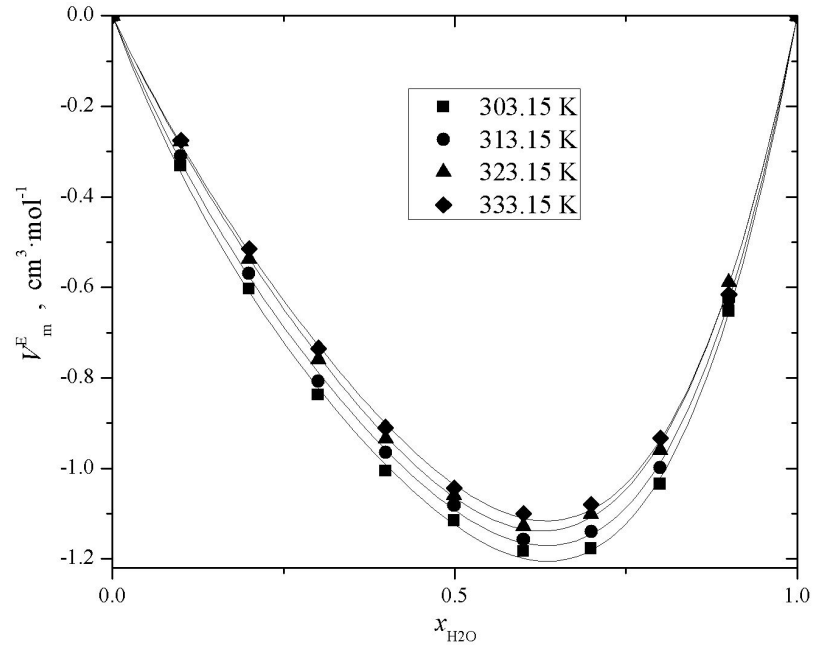

FIGURE 4. Excess molar volume of $\operatorname{AMP}(2)+\mathrm{H}_{2} \mathrm{O}$ (3).

$$
F O=\sum_{i=1}^{n}\left(\rho_{\text {exp }, i}-\rho_{\text {cal }, i}\right)^{2} .
$$

The Design-Expert v.6 software was used to minimize the objective function using a two-level factorial design with 
TABLE IV. Analysis of variance (ANOVA) for the polynomial correlation.

\begin{tabular}{cccccc}
\hline Source & Sum of Squares & DF & Mean Square & $F$ Value & Prob $>F$ \\
\hline Model based on polynomial approach & 0.6 & 3 & 0.2 & 1634.58 & $<0.0001$ \\
$x_{1}$ & 0.2 & 1 & 0.2 & 1616.88 & $<0.0001$ \\
$x_{2}$ & 0.097 & 1 & 0.097 & 789.7 & $<0.0001$ \\
$T$ & 0.023 & 1 & 0.023 & & \\
Residual & 0.032 & 260 & $1.227 \times 10^{-4}$ & & \\
Total & 0.63 & 263 & & & \\
\hline
\end{tabular}

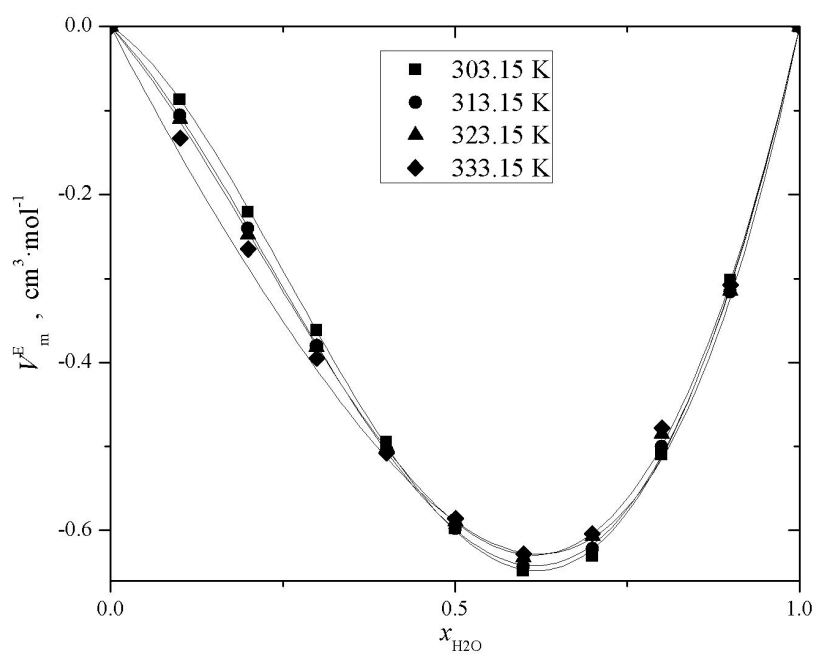

FIGURE 5. Excess molar volume of DEA (2) $+\mathrm{H}_{2} \mathrm{O}$ (3).

three factors $\left(x_{1}, x_{2}\right.$, and $\left.T\right)$. The low and high levels for concentration were fixed in 0 and 1 , while the low and high levels for $\mathrm{T}$ were fixed in 303.15 and $333.15 \mathrm{~K}$. Table IV reports the results for the analysis of variance (ANOVA) that was obtained in this work. Based on a $95 \%$ confidence level, the polynomial correlation was tested to be significant, as the computed $F$ value of 675.52 is much higher than the theoretical $F_{0.05}$ value of 2.37 , which is reported for four degrees of freedom and residual higher than 120. On the other hand, values of "Prob $>F$ " less than 0.05 indicate that the terms of correlation $\left(x_{1}, x_{2}, T\right)$ are significant.

Figure 6 presents an example of the comparison between the experimental values of density and those calculated by the polynomial correlation given by Eq. (16) The experimental points are represented by points in the 3D plot, while the calculated values are represented by the colored surface, and we only show the results at $323.15 \mathrm{~K}$.

The statistical parameters related to the comparison between our experimental data and the calculated values with Eq. (16) are reported in Table V. As can be seen, this method had small values of AAD $(0.82$ and $1.36 \%)$ when the predictions obtained with the polynomial correlation was compared both with our experimental data as the data reported in the literature. However, the values of $\sigma$ and $R$ were not satisfactory, because $\sigma$ was equal to 0.0111 and $0.0162 \mathrm{~g} \cdot \mathrm{cm}^{-3}$;

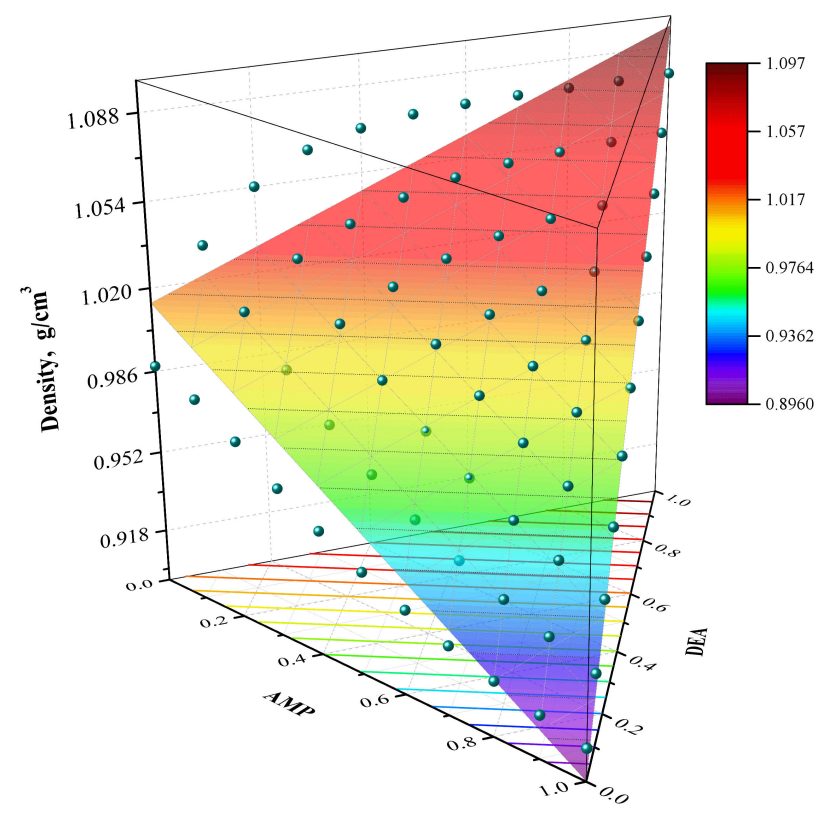

FIGURE 6. Experimental density data (spheres) vs. polynomial correlation (colored surface) at $323.15 \mathrm{~K}$.

while $R$ was equal to 0.9745 and 0.9264 , so we can conclude that this method did not have the best predictive capability.

\subsubsection{Mixing rule test}

We obtained the following equation for the mixing rule, where a dependence with temperature and concentration of the blend was incorporated:

$$
\begin{aligned}
\rho_{m} & =x_{1}\left(-8.5 \times 10^{-4} T+1.1843\right) \\
& +x_{2}\left(-7 \times 10^{-4} T-1.3024\right) \\
& +x_{3}\left(-3.6 \times 10^{-6} T^{2}+1.9 \times 10^{-3} T+0.7544\right) .
\end{aligned}
$$

As can be seen in Eq. (18), the density of the AMP and DEA compounds had a linear dependence with temperature, while the density of the $\mathrm{H}_{2} \mathrm{O}$ compound had a quadratic dependence. These relationships were derived by using both the experimental values of this work, as reported in the literature. Similar to the polynomial correlation, we used a linear regression to adjust the parameters of the mixing rule. 
TABLE V. Statistical parameters of the polynomial correlation and mixing rule.

\begin{tabular}{|c|c|c|c|c|}
\hline Comparison & Points & $\begin{array}{c}A A D \\
\%\end{array}$ & $\begin{array}{c}\sigma \\
\mathrm{g} \cdot \mathrm{cm}^{-3}\end{array}$ & $R$ \\
\hline$\rho_{\text {cal }}$ (polynomial correlation) vs. $\rho_{\exp }$ (obtained in this work) & 264 & 0.82 & 0.0111 & 0.9745 \\
\hline$\rho_{\text {cal }}($ polynomial correlation $)$ vs. $\rho_{\exp }($ from literature $[2,5,10,14,16])$ & 212 & 1.36 & 0.0162 & 0.9264 \\
\hline$\rho_{\text {cal }}$ (mixing rule) vs. $\rho_{\exp }$ (obtained in this work) & 264 & 1.23 & 0.0183 & 0.9676 \\
\hline$\rho_{\text {cal }}\left(\right.$ mixing rule) vs. $\rho_{\text {exp }}$ (from literature $\left.[2,5,10,14,16]\right)$ & 212 & 1.47 & 0.0206 & 0.9278 \\
\hline
\end{tabular}

\begin{tabular}{|c|c|c|c|c|c|c|c|c|c|}
\hline \multirow[b]{2}{*}{$T, K$} & \multicolumn{3}{|c|}{$\operatorname{AMP}(1)+$ DEA (2) } & \multicolumn{3}{|c|}{$\mathrm{AMP}(1)+\mathrm{H} 2 \mathrm{O}(3)$} & \multicolumn{3}{|c|}{ DEA (2) + H2O (3) } \\
\hline & $A_{0}$ & $A_{1}$ & $A_{2}$ & $A_{0}$ & $A_{1}$ & $A_{2}$ & $A_{1}$ & $A_{2}$ & $A_{3}$ \\
\hline 303.15 & -0.6886 & 0.1647 & 0.0238 & -4.501 & 2.1401 & -1.6665 & -2.4002 & 1.5381 & 0.3322 \\
\hline 313.15 & -0.6126 & 0.1178 & 0.1787 & -4.3693 & 2.1341 & -1.4452 & -2.3946 & 1.4103 & 0.14 \\
\hline 323.15 & -0.5884 & 0.1529 & 0.3131 & -4.2601 & 2.1288 & -1.0262 & -2.3589 & 1.3182 & 0.0834 \\
\hline 333.15 & -0.5595 & 0.1752 & 0.2934 & -4.1469 & 2.1648 & -1.1516 & -2.3563 & 1.1849 & -0.0427 \\
\hline
\end{tabular}

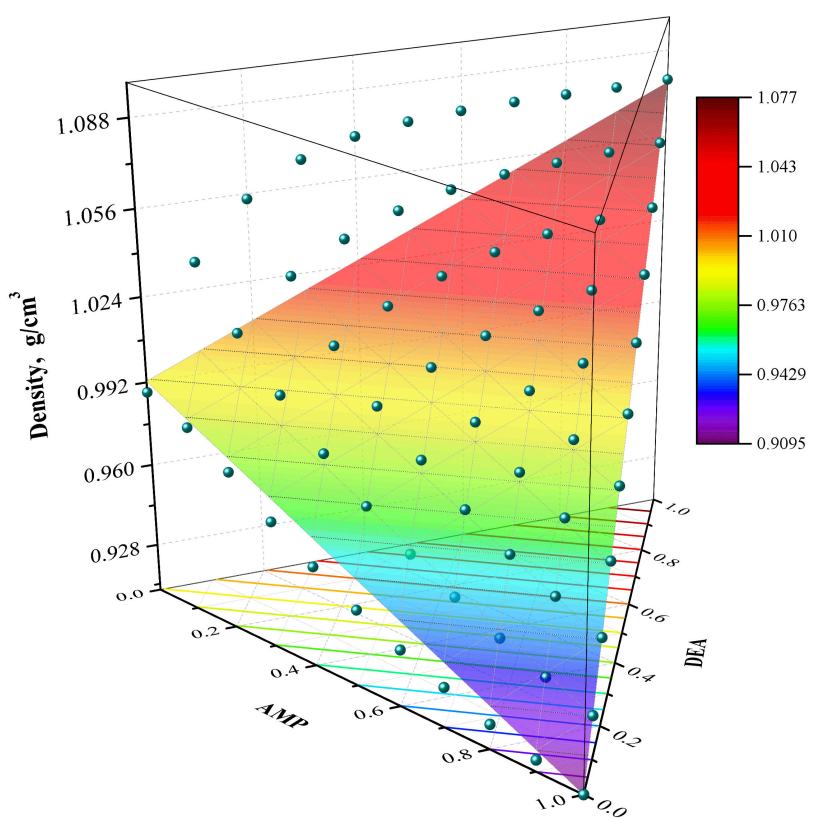

FIGURE 7. Experimental density data (spheres) vs. mixing rule (colored surface) at $323.15 \mathrm{~K}$.

As an example, we chose the temperature of $323.15 \mathrm{~K}$ to show the comparison between the experimental and calculated values; the result is shown in Fig. 7, we can see that although the mixing rule offers a good approximation for most of the experimental points, there is a zone where predictions are not favorable, which is located at the rich concentration in DEA and $\mathrm{H}_{2} \mathrm{O}$.

The results show a good agreement between experimental and calculated densities, as can be seen in Table V. With the Eq. (18) we obtained better approximations to the experimental density obtained by us than to the density reported in the literature, because in the first case, $A A D$ and $\sigma$ was smaller, and $R$ was closer to the unit, as can be seen in Table V.

\subsubsection{Redilich-Kister + Cibulka and Redlich Kister + Singh test}

Table VI reports the parameters that we obtain to predict $V^{E}$ of the binary mixtures by using the Redlich-Kister equation. These parameters were adjusted with the experimental data of this work. In the case of the ternary system, the parameters of the ternary contribution are reported in Table VII, which were calculated following equations proposed by Cibulka and Singh et al.

The Gauss-Newton method was used in both cases (binary and ternary systems) to adjust the best parameters able to minimize the objective function given by:

$$
F O=\sum_{i=1}^{n}\left(V_{\mathrm{exp}, i}^{E}-\rho_{\mathrm{cal}, i}^{E}\right)^{2} .
$$

Table VIII reports the statistical parameters when the experimental excess molar volume is compared with the calculated one. The higher deviation was found at $333.15 \mathrm{~K}$ for the AMP (1) + DEA (2) mixture $(\mathrm{AAD}=3.59 \%)$. The RedlichKister + Cibulka equations had a better performance than the Redlich-Kister + Singh et al. equations, because the first one had an AAD in the range of 1.79 to $2.18 \%$, while the second one had an AAD in the range of 3.71 to $5.56 \%$.

After obtaining the predicted values of the excess molar volume, it is possible to re-calculate the density of the mixture using the following equation:

$$
\rho_{m}=\frac{\sum_{i=1}^{n} x_{i} M-i}{V_{m}^{E}+\sum_{i=1}^{n} \frac{x_{i} M-i}{\rho_{i}}} .
$$




\begin{tabular}{|c|c|c|c|c|c|}
\hline \multicolumn{6}{|c|}{ TABLE VII. Parameters $\left(B_{i}\right.$, in $\left.\mathrm{cm}^{3} \cdot \mathrm{mol}^{-1}\right)$ of the ternary mixtures. } \\
\hline & \multicolumn{5}{|c|}{$T, K$} \\
\hline & Parameters & 303.15 & 313.15 & 323.15 & 333.15 \\
\hline \multirow{3}{*}{ Cibulka [13] } & $B_{0}$ & 16.5655 & 11.6696 & 4.7732 & -1.4911 \\
\hline & $B_{1}$ & -26.5858 & -16.2087 & -2.1535 & 9.64 \\
\hline & $B_{2}$ & -45.8338 & -36.281 & -13.9809 & 8.8364 \\
\hline \multirow{3}{*}{ Singh et al. [14] } & $B_{0}$ & -7.2557 & -5.478 & -0.4208 & 4.7737 \\
\hline & $B_{1}$ & -72.7033 & -55.4515 & -19.3667 & 15.2581 \\
\hline & $B_{2}$ & -53.6987 & -58.9699 & -31.181 & -18.052 \\
\hline
\end{tabular}

TABLE VIII. Statistical parameters of the Redlich-Kister and Cibulka or Singh equations.

\begin{tabular}{|c|c|c|c|c|c|c|}
\hline & & & Points & $A A D$ & $\sigma$ & $\mathrm{R}$ \\
\hline System & Equation & $T, K$ & & $\%$ & $\mathrm{~cm}^{3} \cdot \mathrm{mol}^{-1}$ & \\
\hline \multirow{4}{*}{$\operatorname{AMP}(1)+$ DEA (2) } & & 303.15 & 9 & 2.1 & 0.003 & 0.9984 \\
\hline & & 313.15 & 9 & 1.15 & 0.002 & 0.9993 \\
\hline & & 323.15 & 9 & 1.2 & 0.002 & 0.9995 \\
\hline & & 333.15 & 9 & 3.59 & 0.003 & 0.9983 \\
\hline \multirow{4}{*}{$\operatorname{AMP}(1)+\mathrm{H}_{2} \mathrm{O}(3)$} & & 303.15 & 9 & 1.37 & 0.014 & 0.9992 \\
\hline & Redlich-Kister & 313.15 & 9 & 1.33 & 0.013 & 0.9993 \\
\hline & & 323.15 & 9 & 1.15 & 0.01 & 0.9996 \\
\hline & & 333.15 & 9 & 1.44 & 0.013 & 0.9992 \\
\hline \multirow{4}{*}{$\mathrm{DEA}(2)+\mathrm{H} 2 \mathrm{O}(3)$} & & 303.15 & 9 & 0.85 & 0.005 & 0.9997 \\
\hline & & 313.15 & 9 & 0.83 & 0.006 & 0.9997 \\
\hline & & 323.15 & 9 & 1.44 & 0.008 & 0.9993 \\
\hline & & 333.15 & 9 & 1.22 & 0.008 & 0.9992 \\
\hline \multirow{8}{*}{$\operatorname{AMP}(1)+\operatorname{DEA}(2)+\mathrm{H}_{2} \mathrm{O}(3)$} & & 303.15 & 36 & 2.18 & 0.023 & 0.9937 \\
\hline & Cibulka [13] & 313.15 & 36 & 1.79 & 0.019 & 0.9962 \\
\hline & & 323.15 & 36 & 2.15 & 0.018 & 0.9972 \\
\hline & & 333.15 & 36 & 1.88 & 0.015 & 0.9986 \\
\hline & & 303.15 & 36 & 5.39 & 0.052 & 0.9736 \\
\hline & Singh et al. [14] & 313.15 & 36 & 5.56 & 0.049 & 0.9757 \\
\hline & & 323.15 & 36 & 5.06 & 0.035 & 0.9894 \\
\hline & & 333.15 & 36 & 3.71 & 0.023 & 0.9969 \\
\hline
\end{tabular}

TABLE IX. Statistical parameters of the Redlich-Kister + Cibulka and Redlich-Kister + Singh equations.

\begin{tabular}{|c|c|c|c|c|}
\hline Comparison & Points & $\begin{array}{c}A A D \\
\%\end{array}$ & $\begin{array}{c}\sigma \\
\mathrm{g} \cdot \mathrm{cm}^{-3}\end{array}$ & $R$ \\
\hline$\rho_{\text {cal }}\left(\right.$ Redlich-Kister + Cibulka) vs. $\rho_{\exp }$ (obtained in this work $)$ & 264 & 0.02 & 0.0003 & 0.9999 \\
\hline$\rho_{\text {cal }}($ Redlich-Kister + Cibulka $)$ vs. $\rho_{\exp }($ from literature $[2,5,10,14,16])$ & 212 & 0.11 & 0.0015 & 0.9995 \\
\hline$\rho_{\text {cal }}($ Redlich-Kister + Singh et al. $)$ vs. $\rho_{\exp }$ (obtained in this work) & 264 & 0.03 & 0.0005 & 0.9999 \\
\hline$\rho_{\text {cal }}($ Redlich-Kister + Singh et al. $)$ vs. $\rho_{\exp }($ from literature $[2,5,10,14,16])$ & 212 & 0.12 & 0.0016 & 0.9995 \\
\hline
\end{tabular}

The above equation can be obtained from combining Eqs. (1), (2), and (3).

The excellent agreement between the experimental values and those calculated with the Redlich + Cibulka model is shown in Fig. 8. In this case, the colored surface matches very well with the experimental points at any concentration and temperature of $323.15 \mathrm{~K}$. Because the Redlich + Singh model offers similar results to the Redlich + Cibulka model, the corresponding 3D plot is not included in this work.

The excellent agreement between the experimental and calculated values of density is also can be seen in Table IX, 


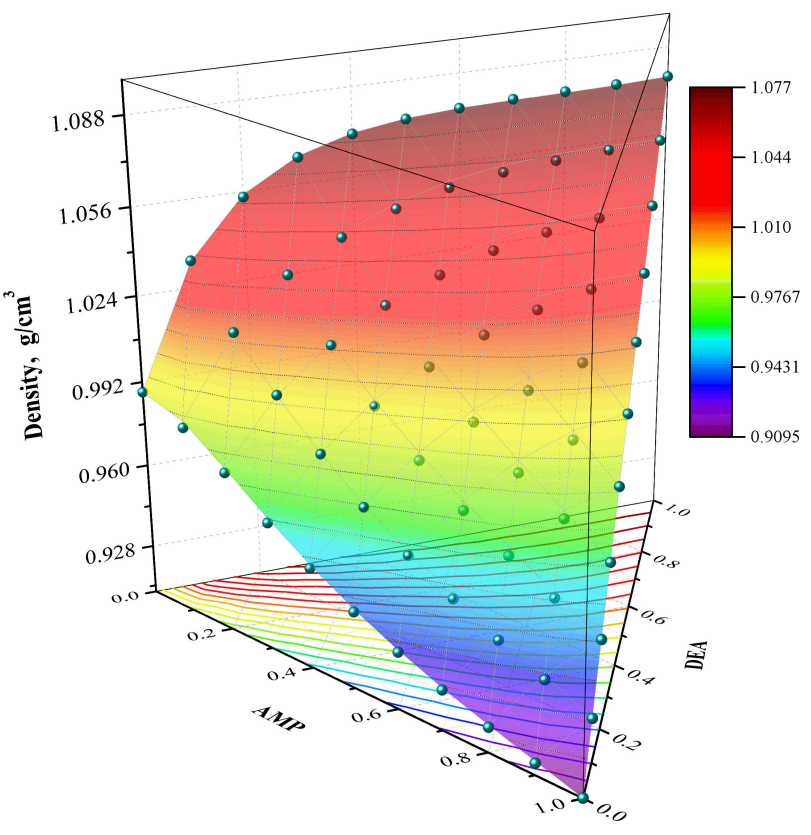

FIGURE 8. Experimental density data (spheres) vs. Redlich + Cibulka equation (colored surface) at $323.15 \mathrm{~K}$.

which shows that both prediction methods (Redlich-Kister + Cibulka and Redlich-Kister + Singh) have an excellent performance.

\section{Conclusions}

Experimental densities were measured using the well-known vibrating tube densimeter, obtaining reliable experimental data with an uncertainty of $0.0002 \mathrm{~g} \cdot \mathrm{cm}^{-3}$. The experimental results on the density of our work include either pure alkanolamines or aqueous mixtures at low and high alkanolamine concentration, covering the entire concentration range and temperatures from 303.15 to $333.15 \mathrm{~K}$. Three methods were tested to establish their prediction capability to calculate the density of the ternary mixture: AMP (1) + DEA (2) + $\mathrm{H}_{2} \mathrm{O}(3)$.

\section{Acknowledgments}

Ramírez-Verduzco thanks the "Instituto Mexicano del Petróleo (IMP)" for granting a scholarship to conclude his postgraduate studies. Finally, special gratitude to Arturo Trejo, Ascención Romero, and Nayereh Mousavi for their useful advice to develop this work. This work was carried as part of the activities of IMP project D.00338.
1. F. Murrieta-Guevara, M. E. Rebolledo-Libreros, A. RomeroMartínez, and A. Trejo, Fluid Phase Equilibr. 150 (1998) 721. https://doi.org/10.1016/S0378-3812(98) 00352-5

2. G. T. Rochelle, Science. 325 (2009) 1652. https://doi. org/10.1126/science.1176731

3. J. Águila-Hernández, R. Gómez-Quintana, F. MurrietaGuevara, A. Romero-Martínez, and A. Trejo, J. Chem. Eng. Data. 46 (2001) 861. https: //doi.org/10.1021/ je0002944

4. Z. Idrisa, J. Hana, S. Jayarathnaa, and D. A. Eimera, Energy Procedia. 114 (2017) 1828. https : / doi.org/10.

5. U. S. P. R. Arachchige, N. Aryal, P. Ghimire, M. Halstensen, and M. C. Melaaen, Ann. T. Nord. Rheol. Soc. 21 (2013) 299. https://doi.org/10.1016/j.egypro. 2013.06 .081

6. C. Chan, Y. Maham, A. E. Mather, and C. Mathonat, Fluid Phase Equilibr. 198 (2002) 239. https://doi.org/10. 1016/S0378-3812(01)00768-3

7. S. J. Yoon, H-S. Lee, H. Lee, J-I. Baek, J.-H. Yoon, and HM. Eum, J. Chem. Eng. Data. 47 (2002) 30. https://doi. org/10.1021/je010196y

8. B. P. Mandal, M. Kundu, and S. S. Bandyophahyay, J. Chem. Eng. Data. 48 (2003) 703. https: // doi.org/10.1021/ je049826x

9. M. E. Rebolledo-Libreros, and A. Trejo, J. Chem. Eng. Data. 51 (2006) 702. https://doi.org/10.1021/je050462y
10. E. Álvarez, F. Cerdeira, D. Gómez-Díaz, and J. M. Navaza, $J$. Chem. Eng. Data. 55 (2010) 994. https://doi.org/10 . 1021/je900739x

11. D. Ma, Q. Liu, C. Zhu, H. Feng and Y. Ma, J. Chem. Thermodynamics. 134 (2019) 5.

12. F. Murrieta-Guevara, and A. Trejo, J. Chem. Eng. Data. 29 (1984) 204. https://doi.org/10.1016/ 0378-3812(93) 87178-4

13. I. Cibulka, Collect. Czech. Commun. 47 (1982) 1414. https: //doi.org/10.1016/0021-9614(84)90149-6

14. P. P. Singh, R. K. Nigam, S. P. Sharma, and S. Aggarwal, Fluid Phase Equilibr. 18 (1984) 333. https://doi.org/ $10.1016 / 0040-6031(85) 85321-1$

15. S. Xu, F. D. Otto, and A. E. Mather, J. Chem. Eng. Data. 36 (1991) 71

16. M. H. Li, and Y. C. Lie, J. Chem. Eng. Data. 39 (1994) 444. https://doi.org/10.1021/je00015a009

17. Y. Maham, T. T. Teng, L. G. Hepler, and A. E. Mather, J. Solution Chem. 23 (1994) 195. https: //doi.org/10.1007/ BE00973546

18. R. M. DiGuillo, R. J. Lee, S. T. Schaeffer, L. L. Brasher, and A. S. Teja, J. Chem. Eng. Data. 37 (1992) 239. https: //doi.org/10.1021/je0000a028 
19. Y.W. Wang, S. Xu, F.D. Otto, and A.E. Mather, Chem. Eng. J. 48 (1992) 31. https://doi.org/10.1016/ 0300-9467(92) 85004-S

20. J. A. Riddick and W. B. Bunger, Organic Solvents: Physi- cal Properties and Methods of Purification, 3th ed. (WileyInterscience, New York, 1970), pp. 66-69

21. C. H. Hsu and M. H. J. Li, J. Chem. Eng. Data. 42 (1997) 502. https://doi.org/10.1021/je960356j 